\title{
Spatio-Temporal Mapping of Water Consumption at Public Institutions: Case of the United Arab Emirates University
}

\author{
M. M. Yagoub ${ }^{1}$ *, Tareefa AlSumaiti ${ }^{2}$, Latifa Ebrahim, Yaqein Ahmed, and Rauda Abdulla \\ ${ }^{1}$ Remote Sensing and GIS, email: myagoub@uaeu.ac.ae \\ ${ }^{2}$ GIS and Environment, email: tareefa@uaeu.ac.ae \\ Department of Geography and Urban Planning, College of Humanities and Social Sciences \\ United Arab Emirates University, P. O. Box 15551, Al-Ain
}

* Corresponding author

Keywords: Water consumption, public institutes, UAE University, GIS, public awaren ess, survey.

\begin{abstract}
:
The United Arab Emirates (UAE) faces water scarcity. Yet, the UAE is one of the highest countries in the per capita water consumption. The United Arab Emirates University (UAEU) is one of the biggest public institutions in the country. On average, the water costs the university annually around two million dirhams. In this study, indoor water consumption at the UAEU is assessed for the period 2016-2017. Geographic Information System (GIS) is utilized to answer where water is highly consumed with in the university (hot spots), when (time), who consume it, why (causes), and how to minimize consumption. It assembles diverse data reside at various departments to gain a better know ledge about the broad patterns of water consumption in the university. The assumption made here is that water consumption is directly proportional to population density and less during winter. The highest water consumption is found at the College of Information Technology (CIT) and this is due to its size and heterogeneity of its activities. The relationship between water consumption and number of students is modeled using least square. The results indicated low corre lation between water consumption and number of students. This may be due to the centralized usage of buildings and movement of students between buildings. Temporal variation showed sharp decrease during July of 2016 and 2017 irrespective of the building type/size and this is associated with summer holidays. The hypothesis of activity-driven consumption showed that the highest water consumption is found at residential build ings due to the longer stay time at hostels. The library showed consistent low water consumption. It is interesting to deduce the library usage while investigating water consumption, but it is a lesson that water consumption could be used as a proxy to reveal number of users at buildings. The water consumption at UAEU is benchmarked with other institutes in UAE and abroad. The result from this study identified sites with the highest water consumption and this could be used to adapt water conservation techniques at these sites. A survey was conducted to understand the students' water consumption behavior, know their willingness to use water conservation methods, and measure their awareness level related to water issues in UAE. The results revealed that half of the respondents are not aware of the water issues. Majority of respondents prefer to drink bottled water than tap water. Majority of respondents are not willing to use grey water or urinals as ways to conserve water due to the lack of knowledge and some physiological reasons. Yet, they are willing to take course designed to teach them how to conserve water and to participate in competitions that reward them for having lower water consumption at hostels.
\end{abstract}

